\title{
ANALISIS DAYA DUKUNG PONDASI TIANG-RAKIT PADA DAERAH RAWAN GEMPA MENGGUNAKAN METODE POULUS DAN PROGRAM NUMERIS PLAXIS
}

\author{
Rini Kusumawardani ${ }^{1}$, Henry Apriyatno ${ }^{2}$, Rizki J ulia Rachmawati ${ }^{3}$, Ririn Anggraini ${ }^{4}$ \\ 1), 2), 3), 4) Jurusan Teknik Sipil, Fakultas Teknik, Universitas Negeri Semarang (UNNES) \\ email: rini.kusumawardani@unnes.ac.id ; email: rizkijulia94@gmail.com ; email: ririn.civil@gmail.com
}

\begin{abstract}
Yogyakarta are situated in the zone with high potential of seismicity. Based on Indonesia map seismicity area, it categorized in a seismic zone 4. The secondary effect of this earthquake phenomena is a soll settlement due to of decreasng of void volume of soil mass. Based on these issues, the foundation system of building is the primary factor which must be considered. This paper revealed the comparation of foundation behavior due to static by using Poulos Method and PLAXS 2D. Pile-raft designed by Poulos method was chosen as a subject of research. Analysis of liquefaction potential, soil settlement, carrying capacity, and the safety factor was analyzed by using CYCLIC 1D, 2D PLAXIS and Methods Poulus. For analysis by the Poulus method reached a soil settelement $4.3 \mathrm{~cm}$ and a safety factor 10.76 . While by using PLAXIS 2D obtained $0.30 \mathrm{~cm}$ and 2,088 for soil settlement and safety factor respectively. Furthermore, a seismic motion of 9.2 scale of Richter mgnitude are injected into analysis resistance of foundation.
\end{abstract}

Keywords : Pile-raft foundation, P oulus Method, soil settlement, safety factor

\begin{abstract}
Abstrak: Kota Yogyakarta merupakan wilayah yang memiliki potesi sesismik yang tinggi berdasarkan peta potensi gempa Indonesia. Dalam peta tersebut dikatakan bahawa Kota Yogyakarta terletak pada zona seismik 4. Bahaya sekunder yang terjadi akbat peristiwa gempa adalah adanya penurunan tanah. Berdasarkan permasalahan ini, pemilihansistem fondasi pada pada suatu bangunan adalah hal yang terpenting. Pada artikel ini dijelaskan mengenai perbandingan mengenai perilaku fondasi akibat beban statik meggunakan metode Poulos dan Plaxis 2D. Fondasi tiang rakit dianalisa dengan meggunakan metode Poulos dan Plaxis 2D. Analisis megenai potensi likuifaksi, penurunan tanah, daya dukung fondasi dan faktor kemanan struktur dianalisis menggunakan CYCLIC 1D, Plaxis 2D dan Metode Poulus. Untuk analisis menggunakan metode Poulos pada fondasi rakit-tiang diperoleh nilai penurunan $4,3 \mathrm{~cm}$ dan faktor keamanan 10,76. Untuk analisis menggunakan Plaxis 2D diperoleh penurunan sebesar 0,30 dan angka keamanan pondasi tiang-rakit sebesar 2,088. Selain itu juga dilakukan analisis mengenai ketahanan fondasi ketika menerima beban gempa dengan skala magnitude 9.2 Richter.
\end{abstract}

Kata kunci : Pondasi tiang-rakit, metode Poulos, penurunan tanah, angka keamanan

\section{PENDAHULUAN}

Daerah Istimewa Yogyakarta merupakan salah satu daerah rawan gempa bumi di Indonesia. Pada tanggal 27 Mei 2006 terjadi gempa tektonik dangkal di Yogyakarta dengan kisaran kekuatan 6,3 skala richter selama 60 detik pada kedalaman $17,1 \mathrm{~km}$. Pusat gempa bumi terletak di dekat pantai pada koordinat $8,007^{\circ}$ LS - $110,286^{\circ}$ BT atau terletak pada posisi $\pm 25 \mathrm{~km}$ barat daya kota Yogyakarta dan $\pm 115 \mathrm{~km}$ selatan kota Semarang (menurut catatan USGS Amerika Serikat) yang mengakibatkan lebih dari 5.700 orang tewas,
37.000 orang cidera, lebih 156.000 rumah dan struktur lainnya hancur total (Elnashai et al, 2006). Kota Yogyakarta merupakan wilayah yang termasuk dalam zona dengan seismisitas cukup tinggi dan aktif yang dikategorikan dalam zona seismik 4 (Departemen Pekerjaan Umum, 2004).

Berdasarkan alasan tersebut di atas, dalam upaya mitigasi bencana gempa bumi pada suatu struktur, maka yang terpenting dalam pelaksanaan perancangan dan pembangunan struktur adalah sistem pondasi yang digunakan. Struktur pondasi berfungsi 
untuk meneruskan beban struktur atas ke lapisan tanah di bawahnya. Setiap pondasi harus mampu mendukung beban sampai batas keamanan yang telah ditentukan, termasuk mendukung beban maksimum yang mungkin terjadi, sehingga perlu adanya desain sistem pondasi yang tepat untuk jenis tanah pada daerah rawan gempa bumi.

Pemilihan jenis pondasi yang digunakan sangat tergantung pada jenis tanah dan struktur yang akan di topang. Pondasi tiangrakit adalah pondasi yang mengkombinasikan antara tiang dan rakit. Alasan pemilihan pondasi tiang-rakit adalah penurunan pondasi terjadi secara bersama-sama dan cocok digunakan pada bangunan yang memiliki luasan bangunan yang besar (Noorlaelasari, 2010). Menurut Poulos (2000) kondisi tanah yang sesuai untuk pondasi tiang-rakit meliputi: lapisan tanah yang terdiri dari lempung keras/kaku; lapisan tanah yang terdiri dari pasir padat; dan tanah berlapis dengan tanah pendukung dibawah pondasi tiang tidak ada lapisan tanah lunak.

Adanya penambahan tiang pada pondasi rakit akan membantu mengatasi masalah penurunan yang terjadi, dengan memanfaatkan tahanan friksi tiang penurunan yang terjadi dapat diminimalisasi. Kedalaman tiang tidak harus mencapai tanah keras karena salah satu konsep pondasi tiang-rakit adalah "floating pile" sehingga tiang dianggap melayang tidak mencapai tanah keras.

Kombinasi kinerja antara komponen rakit, tiang pancang, dan lapisan tanah membuat jenis pondasi tiang-rakit efektif untuk mengurangi penurunan total yang terjadi pada struktur. Komponen rakit diharapkan dapat menahan beban dengan tingkat keamanan yang cukup, sedangkan komponen tiang berperan dalam mereduksi penurunan yang terjadi pada tanah.

\section{STUDI PUSTAKA}

Katzenbach, et al (2000) mendefinisikan pondasi tiang-rakit sebagai jenis pondasi yang bekerja sebagai struktur komposit dengan memanfaatkan tiga elemen penahan beban, yaitu tiang pancang, pondasi rakit, dan jenis tanah di bawah struktur. Oleh karena itu, sebenarnya terdapat empat jenis interaksi yang terjadi dalam struktur pondasi tiang-rakit (Gambar 1). Keempat interaksi tersebut adalah interaksi antara tiang dengan tanah, interaksi antara tiang dengan tiang di sebelahnya, interaksi antara pondasi rakit dengan tanah, dan interaksi antara tiang dengan pondasi rakit.

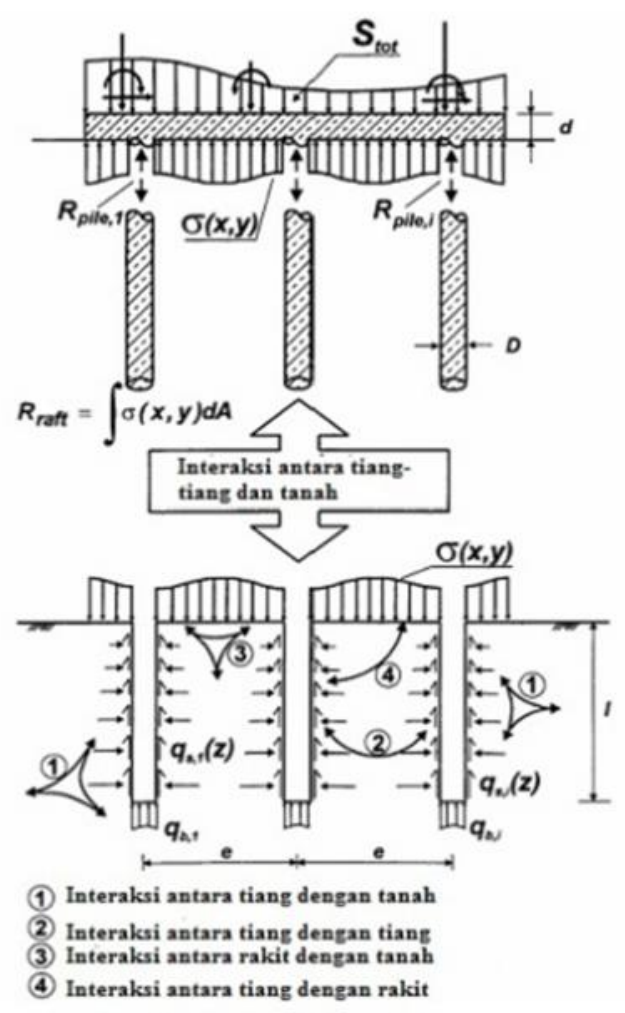

Gambar 1. Jenis interaksi pada pondasi tiang-rakit 
Untuk membuat estimasi awal mengenai perilaku dari pondasi tiang-rakit, sebuah metode mudah dikembangkan oleh Poulos dan Davis (1980) dan Randolph (1994). Metode ini melibatkan dua langkah utama, yaitu estimasi kapasitas beban ultimat dari pondasi dan estimasi perilaku bebanpenurunan lewat hubungan sederhana trilinear.

Hal pertama yang harus dilakukan setelah seluruh data beban diperoleh adalah mengestimasi kapasitas sistem pondasi tiangrakit terhadap beban-beban struktur tersebut.

a) Daya dukung ultimat komponen rakit

$$
\mathrm{p}_{\mathrm{ur}}=\mathrm{K}_{1} \mathrm{~N}_{\mathrm{r}}
$$

dimana:

$\mathrm{p}_{\mathrm{ur}}=$ daya dukung ultimat komponen rakit $(\mathrm{kPa})$

$\mathrm{N}_{\mathrm{r}}=\mathrm{NSPT}$ rata-rata sepanjang kedalaman 1,5 kali lebar komponen rakit (tanpa satuan)

$\mathrm{K}_{1}=$ faktor korelasi untuk komponen rakit (tanpa satuan)

b) Daya dukung ultimat komponen tiang

1) Tahanan friksi ultimat tiang

fs $=2,8 \mathrm{Ns}+10$

dimana:

fs = tahanan friksi ultimat tiang $(\mathrm{kPa})$

Ns = NSPT rata-rata sepanjang tiang (tanpa satuan)

2) Tahanan ujung ultimat tiang

$\mathrm{fb}=\mathrm{K}_{2} \mathrm{~N}_{\mathrm{b}}$

dimana:

$\mathrm{fb}=$ tahanan ujung ultimat tiang $(\mathrm{kPa})$

$\mathrm{N}_{\mathrm{b}}=$ NSPT didekat ujung tiang (tanpa satuan)

$$
\begin{gathered}
\mathrm{K}_{2}=\text { faktor korelasi untuk komponen } \\
\text { tiang (tanpa satuan) }
\end{gathered}
$$

Analisis yang harus dilakukan adalah analisis non-linear yang digunakan untuk mengestimasi hubungan antara beban dengan penurunan primer adalah sebagai berikut.

a) Perhitungan kekakuan komponen rakit $(\mathrm{Kr})$

$$
\mathrm{Kr}=\frac{G}{(1-v)} \beta_{\mathrm{L}} \sqrt{4 C}
$$

$$
\text { dimana: }
$$

$$
\begin{aligned}
\mathrm{Kr}= & \text { kekakuan komponen rakit }(\mathrm{MN} / \mathrm{m}) \\
\mathrm{Gs}= & \text { modulus geser tanah rata-rata } \\
& \text { hingga kedalaman ujung tiang } \\
& (\mathrm{MPa})
\end{aligned}
$$

$\beta z=$ koefisien berdasarkan dimensi rakit

b) Perhitungan kekakuan komponen tiang $(\mathrm{Kp})$

$$
\begin{aligned}
\mathrm{Kp} & =G_{L} T_{0} \frac{\frac{4 \eta}{(1-v) \xi}+\rho \frac{2 \pi}{\zeta} \frac{\mathrm{t}_{\mathrm{i}}(\mu)}{\mu} \frac{L}{r_{U}}}{1+\frac{1}{\pi} \frac{4 \eta}{(1-v) \xi} \frac{\mathrm{t}_{i}(\mu)}{\mu} \frac{L}{r_{U}}} \\
& =\ln \left(\frac{r_{\frac{I m}{}}}{r_{U}}\right)
\end{aligned}
$$

Persamaan 6 diatas mengandung beberapa koreksi, yaitu:

1) Koreksi untuk diameter tiang yang tidak seragam (under-reamed pile)

$\eta=\frac{r_{b}}{r_{u}}$

2) Koreksi untuk tiang end-bearing (tiang fraksi )

$$
\xi=\frac{G_{L}}{G_{D}}
$$

3) Koreksi untuk heterogenitas modulus tanah

$$
\rho=\frac{G}{G}
$$

4) Koreksi untuk rasio kekakuan tiang terhadap tanah

$\lambda=\frac{E}{G}$

5) Koreksi untuk kompresibilitas tiang 


$$
\mu \mathrm{l}=\frac{L}{r} \sqrt{\frac{2}{\varsigma \lambda}}
$$

6) Kekakuan grup tiang

$$
\mathrm{Kp} \text {-sys }=\mathrm{Kp} \sqrt{n_{p}}
$$

dimana:

$$
\begin{aligned}
\mathrm{Kp}= & \text { kekakuan satu tiang tunggal } \\
& (\mathrm{MN} / \mathrm{m}) \\
\mathrm{Kp}-\mathrm{sys}= & \text { kekakuan grup tiang }(\mathrm{MN} / \mathrm{m}) \\
\mathrm{\rho}= & \text { besar beban yang diaplikasikan } \\
& \text { pada rakit } \\
= & \text { panjang tiang }(\mathrm{m}) \\
\mathrm{L}= & \text { radius tiang } \\
\mathrm{Ro}= & \text { modulus geser tanah pada } \\
\mathrm{G} \mathrm{L} & \text { kelamaan ujung tiang (sama } \\
& \text { dengan } \left.\mathrm{G}_{\mathrm{b}}\right)(\mathrm{MPa}) \\
\mathrm{Gavg}= & \text { modulus geser tanah rata-rata } \\
& \text { sepanjang tiang (MPa) } \\
\mathrm{Ep}= & \text { modulus Young tiang (MPa) } \\
\mathrm{V}= & \text { angka poisson tanah } \\
\mathrm{np}= & \text { jumlah tiang }
\end{aligned}
$$

Adapun kekakuan dari sistem pondasi tiang-rakit dapat digambarkan secara matematis sebagai berikut:

$K_{p}=\frac{1-0,6\left(\frac{K_{r}}{K_{p}}\right)}{1-0,6\left(\frac{K_{r}}{K_{p}}\right)} K_{p}$

dimana:

$\mathrm{Kpr}=$ kekakuan sistem pondasi tiang-rakit $(\mathrm{MN} / \mathrm{m})$

$\mathrm{Kp}=$ kekakuan grup tiang $(\mathrm{MN} / \mathrm{m})$

$\mathrm{Kr}=$ kekakuan komponen rakit $(\mathrm{MN} / \mathrm{m})$

Adapun proporsi beban yang ditahan oleh komponen tiang dalam sistem pondasi tiangrakit dapat digambarkan secara matematis sebagai berikut:

$\beta_{p}=\frac{1}{1+\alpha}$ dengan,

$\alpha=\frac{0,2}{1-0,8\left(\frac{K_{I}}{K_{p}}\right)}\left(\frac{K_{I}}{K_{p}}\right)$

Persamaan di atas dapat digunakan untuk membuat kurva tri-linear yang menyatakan hubungan beban-penurunan. kapasitas tiang termobilisasi secara simultan satu sama lain, besarnya P1 (Gambar 2.6) dapat dihitung berdasarkan

$P_{1}=\frac{P_{u}}{\beta_{p}}$

dimana:

$$
\begin{aligned}
\text { Pup }= & \text { kapasitas beban ultimat grup tiang } \\
& (\mathrm{MN}) \\
\mathrm{Bp}= & \text { proporsi beban yang ditahan oleh } \\
& \text { komponen tiang }
\end{aligned}
$$

Pembentukan kurva beban-penurunan tri-linear Poulus

1) Untuk $P \leq P 1$

$$
\mathrm{S}=\frac{P}{K}
$$

dimana:

$$
\begin{aligned}
\mathrm{P}= & \text { beban vertikal yang bekerja }(\mathrm{MN}) \\
\mathrm{Kpr}= & \text { kekakuan aksial dari sistem pondasi } \\
& \text { tiang-rakit }(\mathrm{MN} / \mathrm{m}) \\
\mathrm{S}= & \text { penurunan yang terjadi }(\mathrm{m})
\end{aligned}
$$

2) Untuk $P \geq P 1$

$$
\mathrm{S}=\frac{P 1}{K}+\frac{P-P 1}{K}
$$

dimana:

$$
\begin{aligned}
\mathrm{P}= & \text { beban vertikal yang bekerja }(\mathrm{MN}) \\
\mathrm{S}= & \text { penurunan yang terjadi }(\mathrm{m}) \\
\mathrm{Kpr}= & \text { kekakuan aksial dari sistem pondasi } \\
& \text { tiang-rakit }(\mathrm{MN} / \mathrm{m}) \\
\mathrm{Kr}= & \text { kekakuan aksial dari sistem } \\
& \text { komponen rakit }(\mathrm{MN} / \mathrm{m})
\end{aligned}
$$




\section{METODE PENELITIAN}

Lokasi penelitian adalah di Kampus Universitas Muhammadiyah Yogyakarta, Desa Tlogorejo, Kecamatan Gamping, Kabupaten Sleman, Daerah Istimewa Yogyakarta. Terletak pada koordinat $x$ : 0425010 dan y : 9136836.

Bahan dan alat yang digunakan dalam penelitian ini adalah :

1) Data N-SPT dari Universitas Muhammadiyah Yogyakarta, Desa Tlogorejo, Kecamatan Gamping, Kabupaten Sleman, Yogyakarta.

2) Data gempa diambil pada gempa Kep. Mentawai pada 13 September dengan 7,0 SR dalam format SMC.

3) Software ETABS Versi 9.6.0

ETABS (Extended Three dimensiaon Analysis of Building Systems) adalah salah satu program komputer yang digunakan khusus untuk perencanaan gedung dengan konstruksi beton, baja, dan komposit. ETABS cenderung untuk mendesain gedung bertingkat banyak dengan jumlah joint yang lebih banyak daripada software SAP 2000 (Riza, 2015).

4) Software CYCLIC 1D

CYCLIC 1D adalah program finite element nonlinier yang digunakan untuk simulasi respon gaya lateral dinamis satu dimensi (1D). Hasil yang diperoleh menggunakan program ini adalah informasi mengenai kedalaman tanah yang berpotensi likuifaksi (Kusumawardani, 2015).

5) PLAXIS 2D Versi 9.0

PLAXIS 2D merupakan suatu paket program yang meliputi deformasi elastoplastis statis, pemodelan tanah tingkat lanjut, analisis stabilitas, konsolidasi, analisis keamanan, jaring elemen hingga yang diperbaharui dan aliran statis air tanah (Brinkgreve, 2015).

\section{PEMODELAN DAN ANALISIS}

\section{a) Pemodelan dengan CYCLIC ID}

Seperti yang kita ketahui bahwa untuk mengetahui peristiwa likuifaksi terjadi pada kedalaman berapa meter perlu dilakukan analisis menggunakan software CYCLIC 1D. Secara geoteknik, tanah di Yogyakarta merupakan lapisan tanah pasir yang sangat tebal sampai kedalaman 40 meter dari permukaan tanah. Gradasi tanah pasir relatif seragam dengan nilai N-SPT yang cukup rendah pada daerah dekat permukaan dan cukup tinggi pada kedalaman-kedalaman tertentu. Muka air tanah terletak pada kedalaman 2 meter dari permukaan tanah yang sangat memungkinkan terjadinya peristiwa likuifaksi pada saat terjadi gempa Output dari CYCLIC 1D adalah grafik tegangan efektif dan tekanan air pori.

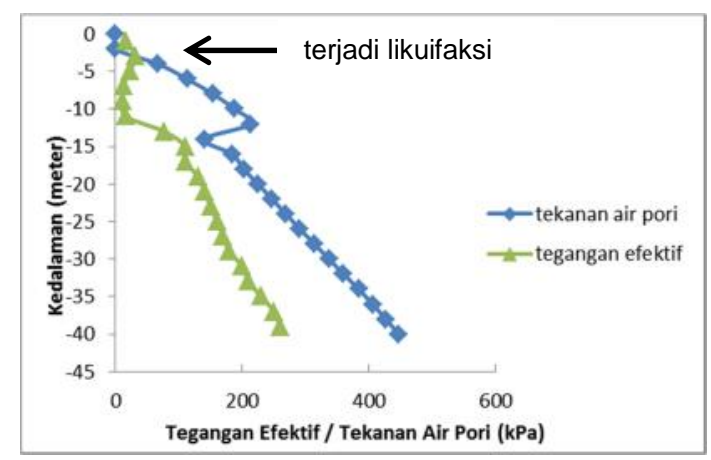

Gambar 2. Hubungan tekanan air pori dan tegangan efektif pada CYCLIC 1D

Likuifaksi dapat terjadi karena meningkatnya tekanan air pori sehingga menyebabkan tegangan efektif tanah berkurang atau bernilai nol. Likuifaksi pada daerah UMY berdasarkan data N-SPT terjadi pada kedalaman 3 meter karena berdasarkan 
hasil CYCLIC 1D tekanan air pori dan tegangan efektif bernilai nol pada kedalaman 3 meter. Potensi munculnya likuifaksi pada suatu elemen tanah berbanding lurus dengan kondisi kejenuhan tanah tersebut. Pada umumnya fenomena likuifaksi akan muncul ketika tanah berada pada kondisi fully saturated.

\section{b) Analisis dengan Metode Poulus}

Metode ini melibatkan estimasi kapasitas beban ultimat dari pondasi dan estimasi perilaku beban-penurunan lewat hubungan sederhana tri-linear. Perhitungan manual pondasi tiang-rakit menggunakan metode Poulos sebagai berikut.

Tabel 1. Analisis Metode Poulus

\begin{tabular}{|c|c|c|c|c|}
\hline \multicolumn{2}{|c|}{ Tahapan } & Notasi & Hasil & Satuan \\
\hline \multicolumn{2}{|c|}{ Daya Dukung Ultimit } & $\mathrm{Lr}$ & 25 & $\mathrm{~m}$ \\
\hline \multirow{3}{*}{\multicolumn{2}{|c|}{ Rakit }} & $\mathrm{Br}$ & 25 & $\mathrm{~m}$ \\
\hline & & K1 & 90 & \\
\hline & & pur & 1743,75 & MN \\
\hline \multirow{10}{*}{$\begin{array}{l}\text { Daya } \\
\text { dukung } \\
\text { ultimat } \\
\text { tiang }\end{array}$} & Tahanan & Ps & 3,05 & \\
\hline & Friksi & & & \\
\hline & Ultimit & & & \\
\hline & Tiang & & & \\
\hline & Tahanan & $\mathrm{Nb}$ & 28 & \\
\hline & ujung & K2 & 325 & \\
\hline & tiang & $\mathrm{fb}$ & 9100 & $\mathrm{KPa}$ \\
\hline & & $\mathrm{Pb}$ & 3,276 & MN \\
\hline & Daya & $\mathrm{Pu}$ & 2730,29 & $\mathrm{MN}$ \\
\hline & $\begin{array}{l}\text { dukung } \\
\text { ultimat } \\
\text { tiang dan } \\
\text { FK }\end{array}$ & FK & 10,76 & \\
\hline \multirow{2}{*}{\multicolumn{2}{|c|}{ Kekakuan pondasi }} & c & 12,5 & \\
\hline & & $d$ & 12,5 & \\
\hline \multirow{4}{*}{\multicolumn{2}{|c|}{ Kekakuan rakit }} & $\mathrm{Kr}$ & $\begin{array}{l}1517,57 \\
3,33\end{array}$ & MN \\
\hline & & $\lambda$ & 1000 & \\
\hline & & $\mu \mathrm{L}$ & 1,06 & \\
\hline & & & 4,44 & \\
\hline \multirow{2}{*}{\multicolumn{2}{|c|}{$\begin{array}{l}\text { Kekakuan satu tiang } \\
\text { Kekakuan grup tiang }\end{array}$}} & $\mathrm{Kp}$ & 1703,15 & MN \\
\hline & & Kp-sys & $\begin{array}{l}21272,4 \\
2\end{array}$ & $\mathrm{MN}$ \\
\hline \multirow{5}{*}{\multicolumn{2}{|c|}{$\begin{array}{l}\text { Kekakuan sistem } \\
\text { pondasi tiang-rakit }\end{array}$}} & Kpr & $\begin{array}{l}23036,7 \\
2\end{array}$ & $\mathrm{MN}$ \\
\hline & & a & 0,015 & \\
\hline & & $\beta p$ & 0,985 & \\
\hline & & P1 & 1001,47 & $\mathrm{MN}$ \\
\hline & & S & 4,34 & $\mathrm{~cm}$ \\
\hline
\end{tabular}

\section{c) Pemodelan menggunakan PLAXIS 2D}

Data hasil desain yang digunakan pada analisis pondasi tiang-rakit menggunakan PLAXIS versi 9.0 adalah sebagai berikut.

1) Ukuran tiang $=0,6 \times 0,6 \mathrm{~m}^{2}$

2) Total jumlah tiang $=156$ buah tiang

3) Jumlah tiang yang dimodelkan $=13$ buah tiang

4) Panjang tiang $=15$ meter

5) Jarak antar tiang $=1,8$ meter

Pada permodelan pondasi tiang-rakit ini menggunakan model plane strain. Permodelan ini digunakan untuk geometri dengan potongan melintang yang relatif seragam. Asumsi pembebanan yang digunakan adalah beban terpusat (point load) yang berada relatif pada satu barisan yang sama sepanjang sumbu $z$. Beban terpusat diasumsikan sebagai beban kolom yang menerus ke pondasi yang diperoleh dari software ETABS. 
Tabel 2. Data Parameter Tanah dalam PLAXIS 2D

\begin{tabular}{|c|c|c|c|c|c|c|}
\hline \multirow{3}{*}{ Simbol } & \multicolumn{5}{|c|}{ LAPISAN } & \multirow[b]{2}{*}{ UNIT } \\
\hline & $(1)$ & (2) & (3) & (4) & (5) & \\
\hline & Pasir Sedang & Pasir Sedang & Lempung Kaku & Pasir Padat & Pasir Padat & \\
\hline Model & Mohr Coulomb & Mohr Coulomb & Mohr Coulomb & Mohr Coulomb & Mohr Coulomb & \\
\hline Jenis & Drained & Drained & Drained & Drained & Drained & \\
\hline sat & 21 & 20 & 18 & 22 & 22 & $\mathrm{kN} / \mathrm{m}^{3}$ \\
\hline unsat & 17 & 18 & 15 & 17 & 17 & $\mathrm{kN} / \mathrm{m}^{3}$ \\
\hline$E^{\prime}$ & 38500 & 38500 & 35000 & 45000 & 45000 & $\mathrm{kN} / \mathrm{m}^{2}$ \\
\hline$v^{\prime}$ & 0,25 & 0,25 & 0,2 & 0,3 & 0,3 & \\
\hline c'ref & 5 & 5 & 30 & 23 & 23 & $\mathrm{kN} / \mathrm{m}^{2}$ \\
\hline$\phi^{\prime}$ & 37,5 & 37,5 & 26 & 41 & 41 & derajat \\
\hline
\end{tabular}

Tabel 3. Data Parameter Tiang dan Rakit dalam PLAXIS 2D

\begin{tabular}{cccl}
\hline Nama & Tiang & Rakit & unit \\
\hline $\mathrm{EA}_{1}$ & $1,99 \mathrm{E}+07$ & $2,350 \mathrm{E}+07$ & $\mathrm{kN} / \mathrm{m}$ \\
$\mathrm{El}$ & $5,98 \mathrm{E}+05$ & $1,958 \mathrm{E}+06$ & $\mathrm{kNm} 2 / \mathrm{m}$ \\
$\mathrm{D}$ & 0,6 & 1 & $\mathrm{~m}$ \\
$\mathrm{~W}$ & 14,40 & 24 & $\mathrm{kN} / \mathrm{m} 2$ \\
$\mathrm{v}$ & 0,2 & 0,2 & \\
\hline
\end{tabular}

Tabel 4. Input Beban Terpusat Pada PLAXIS 2D

\begin{tabular}{cc}
\hline Titik & $\begin{array}{c}\text { Beban } \\
\text { (kN/m) }\end{array}$ \\
\hline $\mathbf{1}$ & 1906,66 \\
$\mathbf{2}$ & 1994,20 \\
$\mathbf{3}$ & 1988,37 \\
$\mathbf{4}$ & 1946,16 \\
$\mathbf{5}$ & 1857,47 \\
$\mathbf{6}$ & 1659,97 \\
\hline
\end{tabular}

Hasil analisis penurunan dengan menggunakan PLAXIS 2D Versi 9.0 adalah sebagai berikut.

1) Rakit

a. Displacement rakit arah $\mathrm{x}$

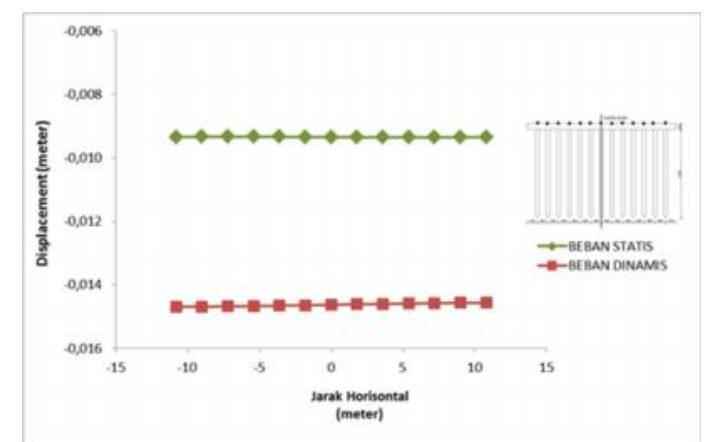

Gambar 3. Grafik displacement rakit arah x
Displacement arah $\mathrm{x}$ adalah perpindahan suatu titik pada rakit akibat pengaruh beban yang bekerja. Ketika struktur rakit diberi beban struktur tanpa gempa, nilai displacement arah $x$ adalah 0,00934 meter pada jarak interval 1,8 meter dari center line kearah $x$ positif maupun negatif. Pada saat terjadi gempa, displacement arah x nilainya naik menjadi 0,01463 meter. Kenaikan nilai displacement sebesar 63,84\% diakibatkan karena komponen rakit menerima beban dinamik (gempa) yang sangat kuat.

b. Displacement rakit arah y

Pada Gambar 4, hubungan displacement dengan jarak horisontal ketika tidak terjadi gempa terlihat bahwa displacement terbesar pada rakit akibat beban struktur terdapat pada jarak horisontal -10,8 meter dari center line (CL) atau dapat dikatakan berjarak 10,8 meter di sebelah kiri CL sebesar 0,176 meter. Hal ini dikarenakan beban struktur yang diterima oleh rakit lebih besar dibanding displacement dengan jarak horisontal 10,8 meter sebesar 0,152 meter. Sedangkan ketika terjadi gempa menunjukkan adanya perbedaan displacement yang sangat signifikan pada jarak horisontal 10,8 meter dari center line sebesar 0,29 meter. Perbedaan nilai displacement akibat pengaruh beban gempa hampir mencapai 100\%. 


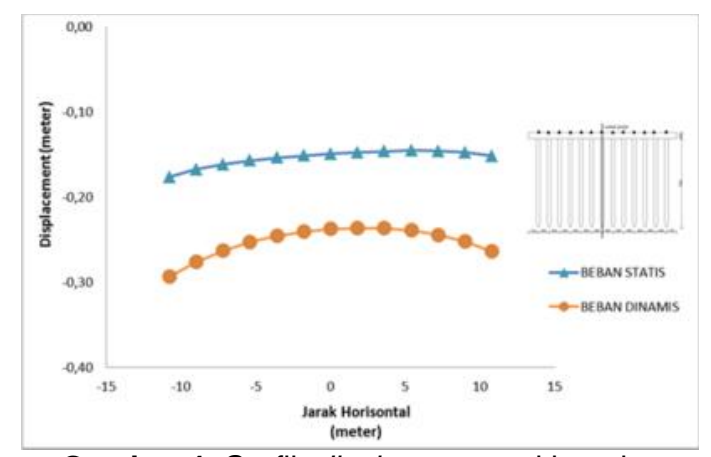

Gambar 4. Grafik displacement rakit arah y

2) Tiang

a. Displacement arah $\mathrm{x}$

Displacement arah $\mathrm{x}$ pada tiang dibagi menjadi dua yaitu persentase total displacement tiang dan persentase rata-rata displacement tiang. Tiang dibagi menjadi tiga titik peninjauan yaitu di atas, tengah, dan bawah. Peninjauan dilakukan setiap interval 1,8 meter dari center line $(C L)$ ke arah $x$ positif maupun negatif. Ketika tiang pada jarak $-10,8$ dari center line mengalami displacement sebesar $0,56 \%$, lalu pada jarak $-9,0$ meter mengalami penurunan menjadi $0,16 \%$ dan kembali mengalami perubahan kenaikan displacement $1,51 \%$ pada jarak 9,0 meter dari center line dan mengalami penurunan pada jarak 10,8 meter yaitu sebesar 1,13\%. Persentase total displacement arah $\mathrm{x}$ tanpa beban gempa, paling besar terjadi pada jarak 9,0 meter (perpindahan cenderung ke arah kanan). Persentase kenaikan total displacement tiang pada saat tidak terjadi gempa adalah $9,38 \%$

Saat terjadi gempa, tiang pada jarak $-10,8$ meter dari center line mengalami displacement sebesar $1,60 \%$ lalu pada jarak $-9,0$ meter mengalami penurunan menjadi $0,72 \%$ dan kembali mengalami perubahan kenaikan displacement $3,10 \%$ pada jarak 7,2 meter dari center line dan mengalami penurunan pada jarak 10,8 meter yaitu sebesar 2,24\%. Persentase total displacement arah $\mathrm{x}$ tanpa beban gempa, paling besar terjadi pada jarak 7,2 meter (perpindahan cenderung ke arah kanan). Persentase kenaikan total displacement tiang terjadi gempa adalah $19,95 \%$.

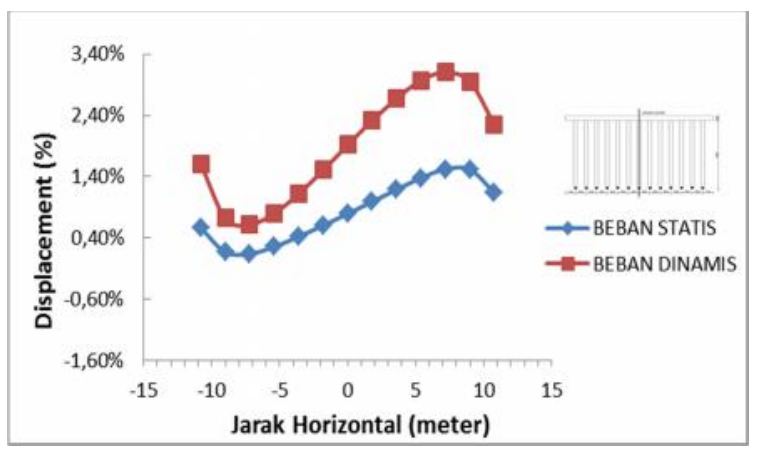

Gambar 5. Grafik displacement total tiang arah x

b. Displacement arah y

Pada Gambar 6 hubungan persentase total displacement tiang dengan jarak horisontal terlihat adanya perbedaan antara tidak terjadi gempa dan terjadi gempa hanya 35\%. Persentase total displacement tiang maksimal pada saat tidak terjadi gempa di jarak horisontal $-10,8$ sebesar $53 \%$ sedangkan gempa sebesar $88 \%$. Hal ini dikarenakan semakin berat beban yang diterima tiang akan mengakibatkan displacement yang tinggi, ditambah dengan pengaruh gempa pada tiang tersebut. 


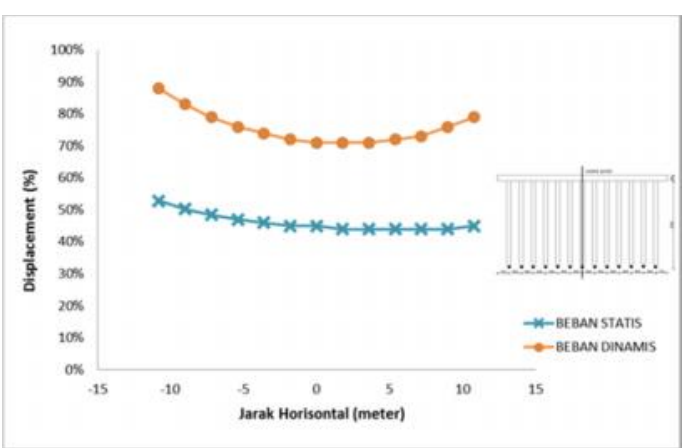

Gambar 6. Grafik persentase total displacement tiang arah y

3) Tanah

a. Displacement arah $x$

Displacement tanah arah $\mathrm{x}$, ketika tanah pada jarak $-5,4$ dari center line mengalami displacement sebesar $0,0041 \%$ lalu pada titik center line 0 meter mengalami penurunan menjadi $0,0025 \%$ dan kembali mengalami penurunan displacement $-0,00044 \%$ pada jarak 5,4 meter dari center line dan mengalami kenaikan pada jarak 12 meter yaitu sebesar 0,015\% dan pada jarak 15,0 meter mencapai nilai $0,016 \%$.

Ketika terjadi gempa displacement tanah arah $\mathrm{x}$, ketika tanah pada jarak -5,4 dari center line mengalami displacement sebesar $0,0028 \%$ lalu pada titik center line mengalami penurunan menjadi $-0,00016 \%$ dan kembali mengalami kenaikan displacement -0,0014\% pada jarak 5,4 meter dari center line dan mengalami kenaikan pada jarak 12,3 meter yaitu sebesar 0,017\% dan pada jarak 15,2 meter mencapai nilai 0,02\%. Grafik displacement tanah arah $\mathrm{x}$ dapat dilihat pada Gambar 7.

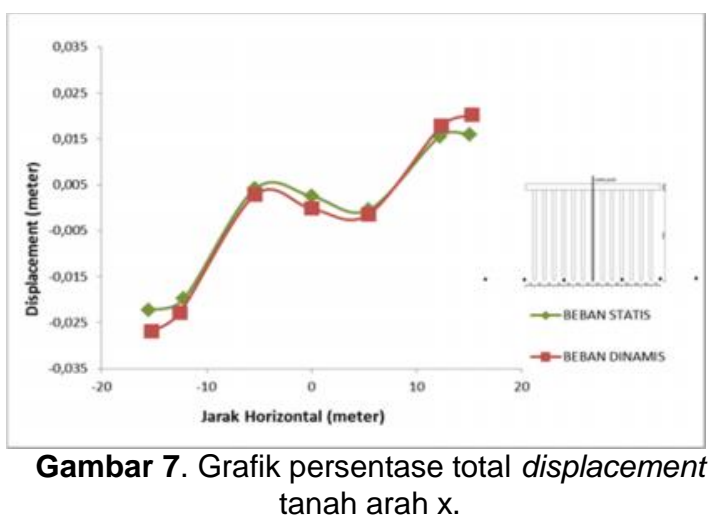

b. Displacement arah y

Berdasarkan Gambar 8 menjelaskan displacement tanah ketika tidak terjadi gempa, pada jarak horisontal -26,54 meter dari CL diperoleh displacement tanah arah y sebesar 0,0125 meter. Tanah mengalami penurunan maksimal pada jarak horisontal $-5,4$ meter dari CL yaitu sebesar 0,145 meter. Sedangkan pada saat gempa, pada jarak horisontal -26,44 meter dari CL diperoleh displacement tanah sebesar 0,0439 meter.

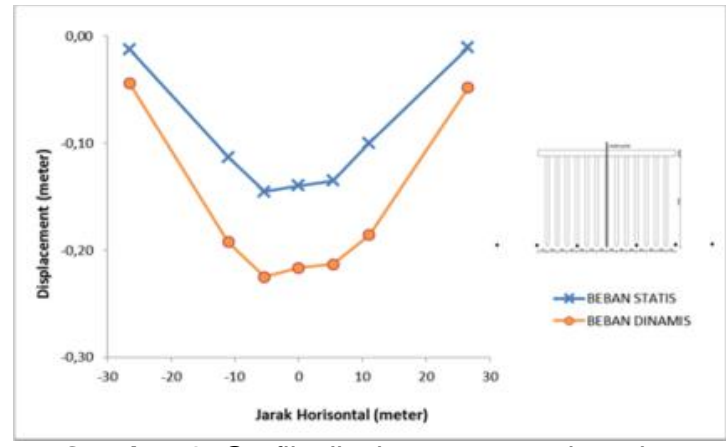

Gambar 8. Grafik displacement tanah arah y

\section{PEMBAHASAN}

Berdasarkan

hasil analisis menggunakan metode Poulus yang telah dibuat, sistem fondasi tiang-rakit berperan sangat signifikan. Hal ini disebabkan besarnya kapasitas tiang dalam menahan beban vertikal dibandingkan sistem rakit. Keberadaan tiang jelas meningkatkan kapasitas total dari sistem pondasi. Semakin besar ukuran, panjang, dan 
jumlah tiang maka proporsi beban yang ditahan oleh sistem tiang akan semakin besar.

Dimensi dan jumlah tiang berpengaruh pada kinerja pondasi. Dimensi dan jumlah tiang sangat terkait pada kekakuan sistem tiang tersebut. Proporsi kemampuan pondasi dalam menahan beban diatasnya digambarkan melalui kekauan komponen pondasi tersebut. Semakin besar dan banyak tiang, maka proporsi beban yang ditanggung tiang juga akan semakin besar.

Penggunaan tiang dalam jumlah banyak memang akan mempengaruhi kinerja pondasi, tetapi dari segi biaya tidak ekonomis. Pada pondasi tiang-rakit, daya dukung rakit harus diperhitungkan. Penggunaan pondasi tiangrakit cocok digunakan pada tanah yang relatif kaku karena diharapkan rakit mampu menahan beban sehingga jumlah tiang dapat direduksi. Ketika jumlah tiang dianggap cukup mampu menyediakan kekuatan pada batas yang diijinkan, maka perubahan dimensi tiang bisa dilakukan untuk memperbesar kemampuan friksi tiang dalam menanggulangi penurunan yang terjadi.

\section{KESIMPULAN}

Kesimpulan yang diperoleh dari desain pondasi tiang-rakit ini adalah sebagai berikut.

1) Penurunan rakit pada system pondasi tiang-rakit dengan pembebanan statis menggunakan metode Poulos sebesar 4,34 $\mathrm{cm}$ dan hasil analisis program numeris tanpa beban gempa didapatkan displacement arah $\mathrm{x}$ sebesar $0,9346 \mathrm{~cm}$ dan displacement arah y sebesar $17,6 \mathrm{~cm}$. Apabila beban gempa dimasukkan sebagai salah satu parameter, maka displacement arah $\mathrm{x}$ sebesar $1,463 \mathrm{~cm}$ dan displacement arah y sebesar $29 \mathrm{~cm}$

2) Untuk penurunan tanah tanpa adanya beban gempa akibat bekerjanya sistem pondasi tiang-rakit dengan pembebanan statis diperoleh nilai displacement arah $\mathrm{x}$ sebesar $1,5 \mathrm{~cm}$ dan displacement arah $\mathrm{y}$ sebesar 14,5 cm. Apabila beban gempa dimasukkan sebagai salah satu parameter, maka displacement arah $\mathrm{x}$ sebesar $2 \mathrm{~cm}$ dan displacement arah y sebesar $23 \mathrm{~cm}$

\section{DAFTAR PUSTAKA}

Brinkgreve, R.B.J., et al. (ed.). 2015. PLAXIS 2D Reference Manual 2015. Netherlands.

De Sanctis, L., Mandolini, A., Russo, G. and Viggiani, C. (2001). Some remarks on the optimum design of piled rafts. personal communication of paper submitted for publication.

Elnashai, A.S., Kim, S.J., Gun, Y.J., and Sidarta, D., "The Yogyakarta Earthquake of May 27, 2006", MAE Center Report No. 07-02, 570, 2007.

Horikoshi, K., \& Randolph, M. F. (1996). Research report No. G:1179: A contribution to optimum design of piled rafts. Nedlands: Department of Civil and Resource Engineering, University of Western Australia.

Katzenbach, R., Arslan, U., \& Moormann, C. (2000). Piled raft foundation projects in Germany. In J. A. Hamsley (Ed.). Design applications of raft foundations (pp. 323391). London: Thomas Telford Publishing.

Kusumawardani, R., Lashari, Nugroho, U. \& Tri Cahyo H. (2015). Analisis Kenaikan Tekanan Air Pori Pada Pasir Yogyakarta Menggunakan Metode Cyclic ShearStrain Controlled, Jurnal Teknik Sipil dan Perencanaan, Nomor 1 Volume 17, Januari 2015

Kusumawardani, R., Suryolelono, K.B., Suhendro,B. \& Rifai, A.. (2016). The 
Dynamic Response of Unsaturated Clean Sand at A Very Low Frequancy, International Journal of Technology, Jurnal Teknik Sipil dan Perencanaan, Volume 1, Januari 2016

Muntohar, Agus Setyo. 2010. Mikro-Zonasi Potensi Likuifaksi dan Penurunan Tanah Akibat Gempa Bumi.

Natasya, B. 2011. Studi Pemakaian Pondasi Tiang-Rakit pada Sebuah Proyek Apartemen di Jakarta dengan Menggunakan Metode Konvensional Poulus dan Plaxis Dua Dimensi. Tugas Akhir di Jurusan Teknik Sipil Universitas Indonesia, Jakarta.

Sulistiyani, D.R., Distya Dea Rena Kalista. 2016. Desain Gedung 20 Lantai +1 Basement di Jalan Diponegoro Semarang. Tugas Akhir Jurusan Teknik Sipil Universitas Negeri Semarang, Semarang.

Poulos, H. G. (2000). Practical design procedures for piled raft foundations. Ed. J. A. Hamsley. London: Thomas Telford Publishing.

Poulos, H. G. (2000). Pile-raft interaction Alternative methods of analysis. Developments in theory. Geomechanics, Ed. D. W. Smith, \& J. P. Carter, Balkema, Rotterdam, 445-468

Poulus, H.G. (2001). Pile Raft Foundations: Design and Applications. Geotechnique 51, No 2, pp 95-113.

Poulos, H. G. (2001). Methods of analysis of piled raft foundations. A report prepared on behalf of technical committee, TC18 on piled foundations, International Society of Soil Mechanics and Geotechnical Engineering.

Prakoso, W. A. and Kulhawy, F. H. (2000). Contribution to piled raft foundation design. Jnl. Geot. and Geoenv. Eng., ASCE, 127(1): 17-24.

Randolph, M. F., \& Wroth, C.P. (1978). Analysis of deformation of vertically loaded piles. Journal Geotechnical Engineering Div, ASCE 104(12): 14651488.
Randolph, M. F. (1994). Design methods for piled groups and piled rafts. Stateof-theart report. Paper presented at the 13th International Conference Soil Mechanics and Foundation Engineering, New Delhi, 61-82.

Richart, Jr., F.R., Hall, Jr., J.R., \& Woods, R.D. (1970). Vibrations of soils and foundations. New Jersey: Prentice-Hall, Inc.

Seed, H.B. and Idriss, I.M., 1971, Simplified Procedure for Evaluation Soil Liquifaction Potential, Journal of soil mechanics and foundation, Division, ASCE, vol.97. No.9, $1249-1273$.

Soebowo, Eko., Adrin Tohari, dan Dwi Sarah. 2007. Studi Potensi Likuifaksi di Daerah ona Patahan Opak Patalan-Bantul Yogyakarta.

Tan, Y.C., \& Chow, C.M. (2004). Design of piled raft foundation on soft ground. Thaher, M., \& Jessberger, H. L. (1991). The behaviour of pile-raft foundations, investigated in centrifuge model tests. Centrifuge 91, Boulder, Colorado, pp. 101-106.

Thaher, M., \& Jessberger, H. L. (1991). Investigation of the behaviour of pile-raft foundations by centrifuge modelling. Proc. 10th European Conference on Soil Mechanics and Foundation Engineering, Vol. 2, pp. 597-603.

Viggiani, C. (2001). Analysis and design of piled foundations. $1^{\text {st }}$ Arrigo Croce Lecture, Rivista Italiana de Geot., 1/2001: 47-75.

http://www.strongmotioncenter.org/cgibin/CESMD. accessed November 10, 2015.

http://www.vsi.esdm.go.id.accessed November 2, 2015. 
138 JURNAL TEKNKSIPIL \&PERENCANAAN Nomor 2 Volume 18 - Juli 2016, hal : 127 - 138 